\title{
ON A DISCRETE MODEL OF OPTIMAL ADVERTISING
}

V.M. Adukov ${ }^{1}$, adukovvm@susu.ac.ru, N.V. Adukova ${ }^{1}$, adnatasha94@mail.ru, K.N. Kudryavtsev ${ }^{1}$, kudrkn@gmail.com.

${ }^{1}$ South Ural State University, Chelyabinsk, Russian Federation.

The continuous models are considered in the most works on optimal advertising. Articles on the discrete-time models are more rare because in this case it is difficult to obtain an explicit solution. In this paper a new discrete model of optimal advertising for a monopolist-seller of a new goods is proposed. In the model, the dynamics is given by a nonlinear difference equation. The non-linearity depends on a parameter $\sigma, 0<\sigma<1$, i.e. a continuous family of the models is considered. The discrete versions of the Vidale - Wolfe model and the Sethi model are particular cases of this model. The seller's problem is to maximize its profit up to the finite horizon $T$ by the optimal advertising expenditure. This problem is a discrete multistep optimal control problem, where an advertising expenditure is a control variable. For our model the optimal control problem can be solved explicitly. The Bellman method of dynaming programming is used to study the problem. Explicit recurrence relations for the optimal control and the market share up to the step $t$, $t=1, \ldots, T$, are obtained under the assumption that the difference equation of the model has a solution. Sufficient conditions on the parameters of the model, which ensure the existence of a solution, are found. The proposed algorithm is implemented as the procedure OptimalAdvertising in the package Maple. Numerical experiments with the procedure were carried out.

Keywords: advertising expenditures; optimal control; discrete model; dynamical programming.

\section{Introduction}

One of the first models that describes an influence of advertising costs on the market share of a monopolistic firm was proposed by M.L. Vidale and H.B. Wolfe in 1957 [1]. In the model, the dynamics of the sales rate $s(t)$ is given by the following differential equation

$$
\dot{s}(t)=\gamma u(t)[m-s(t)]-\delta s(t), \quad s\left(t_{0}\right)=s_{0},
$$

where $u(t)$ is the advertising effort, i.e. a control variable. Here $m$ is a saturation level of the sale rate, $\gamma$ is a response constant characterizing efficiency of advertising, and $\delta$ is a decay constant that determines the rate at which consumers are lost due to product obsolescence.

The classical monopoly model having numerous application was suggested by S.P. Sethi in 1983 [2]. Here the dynamics of the market share $x(t)$ is given by the non-linear differential equation

$$
\dot{x}(t)=\rho u(t) \sqrt{1-x(t)}-\delta x(t), \quad x\left(t_{0}\right)=x_{0} .
$$

The continuous models are considered in the most works on optimal advertising. Articles on the discrete-time models are more rare (see, however, [3-5]) because in this case it is difficult to obtain an explicit solution. 
But the discrete-time models are often preferable in view of the discrete nature of the decisions about funding and promotions.

In the present work, we propose a new discrete model of optimal advertising. The discrete versions of the Vidale - Wolfe model and the Sethi model are particular cases of this model. Note that the model corresponds to all desirable properties [6].

\section{Generalized Sethi model}

Let us consider the problem of finding of the optimal cost of advertising effort for a monopolistic firm that entered the market with a new product. We use a dynamic model in discrete time.

Let $t=1, \ldots, T$ be decision points in time (steps of a dynamic process), $X(t)$ a market share at time $t$ (where $X(t) \in[0,1]), X_{0}=X(0), u(t)$ - an advertising expenditure rate at time $t, \rho$ - a response constant, $\delta \in[0,1]$ - a market share decay constant, $\sigma \in(0,1)$ - a non-linearity parameter of the model. The parameter $\rho$ determines the effectiveness of advertising, and $\delta$ determines the rate at which consumers are lost due to product obsolescence, forgetting, etc.

We consider a generalization of discrete version of the Sethi model [2,7]. In our model the dynamics of $X(t)$ is given by the following difference equation

$$
X(t+1)=(1-\delta) X(t)+\rho u(t)[1-X(t)]^{1-\sigma}, t \in[0 ; T), X(0)=X_{0} .
$$

It is required that $\delta, \rho, \sigma$ are such that $X(t) \in[0,1]$ at any step $t$.

A choose of the additional term in the form $\rho u(t)[1-X(t)]^{1-\sigma}$ can be explained as in the Sethi model (i.e. for $\sigma=1 / 2$ ). The function $[1-X(t)]^{1-\sigma}-[1-X(t)]$ represents as

$$
[1-X(t)]^{1-\sigma}-[1-X(t)]=\sigma X(t)[1-X(t)]+\frac{\sigma(\sigma+1)}{2} X^{2}(t)+\ldots,
$$

and, for sufficiently small $X(t)$, this difference is proportial to $X(t)[1-X(t)]$. Thus, as in $[2]$,

$$
\rho u(t)[1-X(t)]^{1-\sigma} \approx \rho u(t)(1-X(t))+\sigma \rho u(t) X(t)(1-X(t)) .
$$

The term $\rho u(t)(1-X(t))$ is a response to advertising that acts positively on the unsold portion $(1-X(t))$ of the market. The term $\sigma \rho u(t) X(t)(1-X(t))$ can be considered as an additional process of word-of-mouth communication between consumers comprising the sold portion $X(t)$ and those comprising the unsold portion $(1-X(t))$.

Advertising rate $u(t)$ is a control variable of the dynamic system. The control sequence is a vector

$$
u=(u(0), u(1), \ldots, u(T-1)) .
$$

The control variable $u(t)$ is used to find the optimal advertising expenditure in order to obtain the maximal profit at the time $t=T$.

In our model the discounted profit functional is given by the formula:

$$
J=\frac{m X(T)}{(1+r)^{T}}+\sum_{k=0}^{T-1} \frac{m X(k)-c u^{1 / \sigma}(k)}{(1+r)^{k}} .
$$

Here $m$ is the revenue potential (a margin per unit product), $r$ is the discount rate, $c$ is the coefficient characterizing the cost of advertising. In the sequel we scale the profit functional $J$ such that $c=1$. 
The part of the profit functional $J$ corresponding to the advertising expenditure is the term $-\sum_{k=0}^{T-1} \frac{c u^{1 / \sigma}(k)}{(1+r)^{k}}$. We use the non-linear advertising expenditure to take into account a decreasing response of marketing efforts to the firm profit $(0<\sigma<1)$. The case when the cost of the advertising expenditure is a quadratic function $u^{2}(k)$ has often been studied in the literature (see $[8,9])$. We consider more general situation when the non-linearity parameter $1 / \sigma \in(1, \infty)$. Note that in this case the optimal control problem can be solved explicitly.

An equivalent approach is a transference of the non-linearity into the dynamic equation (3) (see, e.g., $[5,10]$ ). Then we can use the linear function of the advertising expenditure in the profit functional. For a further discussion of this issue, see [11].

\section{Solving of the Optimal Control Problem}

In this section we obtain a recurrence relation for optimal control by the dynamic programming method [12]. In this multi-step method it is necessary to construct the Bellman function

$$
V^{(0)}(X(0)), V^{(1)}(X(1)), \ldots, V^{(T)}(X(T))
$$

and the control sequence $u^{*}=\left(u^{*}(0), u^{*}(1), \ldots, u^{*}(T-1)\right)$.

Solving of the problem is carried out in reverse order, starting with the final step $T$. The Bellman function at the step $T$ is

$$
V^{(T)}(X(T))=\max _{u(T) \geqslant} \frac{m X(T)-u^{1 / \sigma}(T)}{(1+r)^{T}}=\frac{m X(T)}{(1+r)^{T}}
$$

because the control $u(T)$ is absent at this step. Recall that we suppose that $c=1$. Let us write $V^{(T)}(X(T))$ in the following form:

$$
V^{(T)}(X(T))=\frac{m}{(1+r)^{T}}\left[\alpha_{T} X(T)+\beta_{T}\right] .
$$

where $\alpha_{T}=1, \beta_{T}=0$.

The Bellman function at the step $k$ is defined by the formula

$$
V^{(k)}(X(k))=\max _{u(k) \geqslant 0} W(k, X(k), u(k))=\max _{u(k) \geqslant 0}\left[\frac{m X(k)-u^{1 / \sigma}(k)}{(1+r)^{k}}+V^{(k+1)}\right],
$$

where $k=T-1, \ldots, 0$. This definition means that we must optimize the advertising expenditure at the step $k$ taking into account the sales $X(k)$ achieved at this moment. The value $u(k)=u^{*}(k)$, for which the function $W(k, X(k), u(k))$ has the maximum, is the desired control at the point $k$. It is clear that the value $V^{(0)}(X(0))$ is the maximal value of the profit functional $J$.

The basic results of the work are the following two theorems.

Theorem 1. Let $\delta, m, \rho, r, \sigma$ be the parameters of the model such that $X(t) \in[0,1]$ for all $t=1, \ldots, T$. Then a solution of the optimal control problem exists, and 
the sequence $V^{(0)}(X(0)), V^{(1)}(X(1)), \ldots, V^{(T)}(X(T))$ and the optimal control sequence $u^{*}=\left(u^{*}(0), u^{*}(1), \ldots, u^{*}(T-1)\right)$ are obtained by the formulas

$$
\begin{aligned}
& V^{(k)}(X(k))=\frac{m}{(1+r)^{T}}\left[\alpha_{k} X(k)+\beta_{k}\right], \\
& u^{*}(k)=\left(\frac{m \sigma \rho \alpha_{k+1}}{(1+r)^{T-k}}\right)^{\frac{\sigma}{1-\sigma}}[1-X(k)]^{\sigma},
\end{aligned}
$$

where

$$
\begin{gathered}
\alpha_{k}=\alpha_{k+1}\left[(1-\delta)-(1-\sigma) \rho\left(\frac{m \sigma \rho \alpha_{k+1}}{(1+r)^{T-k}}\right)^{\frac{\sigma}{1-\sigma}}\right]+(1+r)^{T-k}, \\
\beta_{k}=\beta_{k+1}+(1-\sigma) \rho\left(\frac{m \sigma \rho \alpha_{k+1}}{(1+r)^{T-k}}\right)^{\frac{\sigma}{1-\sigma}} .
\end{gathered}
$$

and $\alpha_{T}=1, \beta_{T}=0$. Here $X(k)$ is given by the following linear difference equation

$$
X(k+1)=\left[1-\delta-\rho\left(\frac{m \sigma \rho \alpha_{k+1}}{(1+r)^{T-k}}\right)^{\frac{\sigma}{1-\sigma}}\right] X(k)+\rho\left(\frac{m \sigma \rho \alpha_{k+1}}{(1+r)^{T-k}}\right)^{\frac{\sigma}{1-\sigma}}
$$

which is obtained from (3) under $u(k)=u^{*}(k)$.

Proof.

Let us prove the theorem by induction on $k=T-1, \ldots, 1,0$.

For $k=T-1$ we have

$$
V^{(T-1)}(X(T-1))=\max _{u(T-1) \geqslant 0} W^{(T-1)}=\max _{u(T-1) \geqslant 0}\left[\frac{m X(T-1)-u^{1 / \sigma}(T-1)}{(1+r)^{T-1}}+V^{(T)}\right] .
$$

Substitute $X(T)$ from (3) into $V^{(T)}$. We get

$$
\begin{aligned}
& W^{(T-1)}=\frac{m X(T-1)-}{u^{1 / \sigma}(T-1)}+ \\
& \quad+\frac{m}{(1+r)^{T-1}}\left((1-\delta) X(T-1)+\rho u(T-1)[1-X(T-1)]^{1-\sigma}\right) .
\end{aligned}
$$

It is easy to see that the function $W^{(T-1)}$ of the variable $u(T-1)$ achieves its maximum at the point

$$
u^{*}(T-1)=\left(\frac{m \rho \sigma}{(1+r)}\right)^{\frac{\sigma}{1-\sigma}}[1-X(T-1)]^{\sigma} .
$$

Hence formula (6) is true at $k=T-1$ and we obtain

$$
\begin{aligned}
& V^{(T-1)}(X(T-1))= \\
& =\frac{m}{(1+r)^{T}}\left[\left((1+r)+(1-\delta)-\rho(1-\sigma)\left(\frac{m \sigma \rho}{1+r}\right)^{\frac{\sigma}{1-\sigma}}\right) X(T-1)+\rho\left(\frac{m \sigma \rho}{1+r}\right)^{\frac{\sigma}{1-\sigma}}\right] .
\end{aligned}
$$


Denote

$$
\alpha_{T-1}=(1-\delta)-\rho(1-\sigma)\left(\frac{m \sigma \rho}{1+r}\right)^{\frac{\sigma}{1-\sigma}}+(1+r), \quad \beta_{T-1}=\rho(1-\sigma)\left(\frac{m \sigma \rho}{1+r}\right)^{\frac{\sigma}{1-\sigma}}
$$

Therefore

$$
V^{(T-1)}(X(T-1))=\frac{m}{(1+r)^{T}}\left[\alpha_{T-1} X(T-1)+\beta_{T-1}\right]
$$

where $\alpha_{T-1}, \beta_{T-1}$ are found by (7), (8) at $k=T-1$.

Suppose that at the step $k+1$ we have

$$
V^{(k+1)}(X(k+1))=\frac{m}{(1+r)^{T}}\left[\alpha_{k+1} X(k+1)+\beta_{k+1}\right]
$$

Find now $V^{(k)}(X(k))=\max _{u(k) \geqslant 0} W^{(k)}$ at the point $k$. Here

$$
\begin{gathered}
W^{(k)}=\frac{m X(k)-u^{1 / \sigma}(k)}{(1+r)^{k}}+V^{(k+1)}(X(k+1))= \\
=\frac{m X(k)-u^{1 / \sigma}(k)}{(1+r)^{k}}+\frac{m}{(1+r)^{T}}\left[\alpha_{k+1} X(k+1)+\beta_{k+1}\right] .
\end{gathered}
$$

A stationary point of the function $W^{(k)}$ is

$$
u^{*}(k)=\left(\frac{m \sigma \rho \alpha_{k+1}}{(1+r)^{T-k}}\right)^{\frac{\sigma}{1-\sigma}}[1-X(k)]^{\sigma} .
$$

Since

$$
\left(W^{(k)}\right)^{\prime \prime}=-\frac{1-\sigma}{(1+r)^{k} \sigma^{2}} u^{\frac{1-2 \sigma}{\sigma}}(k)<0
$$

then $W^{(k)}$ has a maximum at the point $u^{*}(k)$. Hence the optimal position control $u^{*}(k)$ is defined by formula (6).

Now we can find $V^{(k)}(X(k))=\left.W^{(k)}\right|_{u(k)=u^{*}(k)}$ :

$$
\begin{aligned}
& V^{(k)}(X(k))= \\
& =\frac{m}{(1+r)^{T}}\left\{\left[(1-\delta) \alpha_{k+1}-(1-\sigma) \rho \alpha_{k+1}\left(\frac{m \sigma \rho \alpha_{k+1}}{(1+r)^{T-k}}\right)^{\frac{\sigma}{1-\sigma}}+(1+r)^{T-k}\right] X(k)\right. \\
& \left.+\beta_{k+1}+\left(\frac{m \sigma \rho \alpha_{k+1}}{(1+r)^{T-k}}\right)^{\frac{\sigma}{1-\sigma}}\right\} .
\end{aligned}
$$

Thus,

$$
V^{(k)}(X(k))=\frac{m}{(1+r)^{T}}\left[\alpha_{k} X(k)+\beta_{k}\right],
$$

where $\alpha_{k}, \beta_{k}$ are found by formulas (7) и (8). This completes the proof. 
The statements of the theorem for $\sigma=1 / 2$ were obtained previously in [13].

Now we give some sufficient condition on the parameters of the model guaranteeing the requirement $X(t) \in[0,1]$ for a solution of the optimal control problem. We need the following lemmas.

Lemma 1. Let $\left\{\alpha_{k}\right\}_{k=0}^{T}$ be the sequence defining by recurrence relation (7)

$$
\alpha_{k}=\alpha_{k+1}\left[(1-\delta)-(1-\sigma) \rho\left(\frac{m \sigma \rho \alpha_{k+1}}{(1+r)^{T-k}}\right)^{\frac{\sigma}{1-\sigma}}\right]+(1+r)^{T-k}, \quad \alpha_{T}=1 .
$$

If the condition

$$
m \sigma \rho^{\frac{1}{\sigma}}<r+\delta
$$

is hold then the numbers $b_{k}=\rho\left(\frac{m \sigma \rho \alpha_{k}}{(1+r)^{T-k+1}}\right)^{\frac{\sigma}{1-\sigma}}$ are satisfied the inequalities

$$
b_{k}<1, k=0,1, \ldots, T \text {. }
$$

Proof.

By the definition of $b_{k}$ we have that inequalities (11) are equivalent to

$$
\alpha_{k}<\frac{(1+r)^{T-k+1}}{m \sigma \rho^{\frac{1}{\sigma}}}
$$

For $k=T$ the inequality holds because $\delta \in[0,1]$. Suppose that $\alpha_{k+1}<\frac{(1+r)^{T-k}}{m \sigma \rho^{\frac{1}{\sigma}}}$. Then it follows from (7) and (10) that

$$
\alpha_{k}<\alpha_{k+1}(1-\delta)+(1+r)^{T-k}<\frac{(1+r)^{T-k}}{m \sigma \rho^{\frac{1}{\sigma}}}\left[1-\delta+m \sigma \rho^{\frac{1}{\sigma}}\right]<\frac{(1+r)^{T-k+1}}{m \sigma \rho^{\frac{1}{\sigma}}} .
$$

Lemma 2. If inequality (10) is hold, then the solution $X(t)$ of eqution (9) satisfies to the condition $X(t) \in[0,1]$ for any initial condition $X(0)=X_{0}, X_{0} \in[0,1]$.

Proof.

Rewrite equation (9) in the form

$$
X(k+1)=X(k)(1-\delta)+[1-X(k)] b_{k},
$$

where $b_{k}=\rho\left(\frac{m \sigma \rho \alpha_{k}}{(1+r)^{T-k+1}}\right)^{\frac{\sigma}{1-\sigma}}$.

We have $b_{k} \in[0,1]$, by lemma (1). Thus $1-\delta$ and $b_{k} \in[0,1]$.

For $k=0$ the initial value $X_{0}$ belongs to the segment $[0,1]$.

Hence $X(1)=X(0)(1-\delta)+[1-X(0)] b_{0}$ also belongs to $[0,1]$ as the convex combination of the points $1-\delta$ and $b_{0}$.

Suppose that $X(k) \in[0,1]$. From equation (12) it follows that $X(k+1) \in[0,1]$ as the convex combination of the points $1-\delta$ and $b_{k}$. The lemma is proved by induction on $k$. 
Theorem 2. If inequality (10) is hold, then the sequences

$$
\begin{gathered}
u^{*}=\left(u^{*}(0), u^{*}(1), \ldots, u^{*}(T-1)\right), \\
V^{(0)}(X(0)), V^{(1)}(X(1)), \ldots, V^{(T)}(X(T))
\end{gathered}
$$

from theorem (1) are the solution of the optimal control problem, and

$$
\max _{u} J(u)=V^{(0)}(X(0)) .
$$

Proof.

By theorem (1), if $X(t) \in[0,1]$ for all $t=1, \ldots, T$, then a solution of the optimal control problem exists and can be found by formulas $(5)-(9)$. On the other hand, if inequality (10) is hold, then, by lemma (2), the solution $X(t)$ of eqution (9) satisfies to the condition $X(t) \in[0,1]$. Thus, in theorem (1) we construct the solution of the optimal control problem under condition (10).

\section{Algorithm and Example}

Theorems (1) - (2) allow to propose the following algorithm for finding the optimal advertising expenditure.

\section{Algorithm of Optimal Advertising.}

Input: $T \in \mathbb{N}$ is a number of dicision points; $X_{0} \in[0,1]$ is a initial market share; $\delta \in[0,1]$ is a market share decay constant; $m$ is a marget per unit product (the revenue potential); $\rho$ is the coefficient of effectiveness of advertising; $r$ is the discount rate at the initial point in time; $\sigma \in(0,1)$ is the nonlinearity parameters of the model.

Output: $u^{*}=\left(u^{*}(0), u^{*}(1), \ldots, u^{*}(T-1)\right)$ is the optimal control sequence; $V^{(0)}(X(0)), V^{(1)}(X(1)), \ldots, V^{(T)}(X(T))$ is the sequence of the value of the Bellman function $V^{(0)}(X(0))$ is the maximal value of the profit functional); $X(k)$ is the fraction of the total market at the step $k=T$.

Step 1. Initialization.

Set the initial values of the input parameters.

Step 2. Verification of $X_{0}, \delta, \sigma$.

If $X_{0} \notin[0,1]$, or $\delta \notin[0,1]$, or $\sigma \notin(0,1)$ then STOP.

Step 3. Verification of the sufficient condition.

If test $:=\frac{1-\delta+m \sigma \rho^{1 / \sigma}}{1+\mathrm{r}} \geq 1$ then STOP.

Step 3. Finding $\alpha_{k}, \beta_{k}$.

The coefficients $\alpha_{k}, \beta_{k}$ is defined by formulas (7), (8) with the initial values $\alpha_{T}=1$, $\beta_{T}=0$.

Step 3. Finding $X(k)$.

The fraction of the total market $X(k)$ is found from linear difference equation (9) by the initial value $X(0)=X_{0}$. 
Step 4. Finding $V(k), u^{*}$.

The Bellman functions $V^{(k)}$ and the optimal control $u^{*}(k)$ is found by formulas (5), (6).

\section{Step 5. End of the algorithm.}

The algorithm was implemented as the Maple procedure OptimalAdvertising. We pass to the procedure the following parameters: $\mathrm{T}, \mathrm{X} 0:=\mathrm{X}_{0}, \delta, \mathrm{m}, \rho, \mathrm{r}, \sigma$. The procedure returns the vectors $\mathrm{U}, \mathrm{V}, \mathrm{X}$ and constracts the plots point $\mathrm{U}$, point $\mathrm{V}$, point $\mathrm{X}$.

The following example shows how to call the procedure.

\section{Example 1.}

$>$ restart; with(plots):

$>\mathrm{T}:=24 ; \mathrm{XO}:=0.5 ;$ delta: $=0.2 ; \mathrm{m}:=0.6 ; \mathrm{rho}:=0.5 ; \mathrm{r}:=0.1 ;$ sigma:=0.8;

$>$ OptimalAdvertising ( $\mathrm{T}, \mathrm{X} 0$, delta, $\mathrm{m}, \mathrm{rho}, \mathrm{r}, \mathrm{sigma}$ );

the total cost of advertising $=3.565690$

the value of the profit functional $=1.459383$

the maximal value of the profit functional=1.479754

$>\mathrm{U}[10]$;

\subsection{5}

$>\mathrm{V}[10]$;

\subsection{3}

$>\mathrm{X}[10]$;

\subsection{8}

The procedure returns the optimal control sequence $U$, the sequence of the value of the Bellman function $\mathrm{V}$, and the fraction of the total market X. Moreover, the procedure finds the total cost of advertising $\operatorname{sum} U=\sum_{k=0}^{T-1} u^{*}(k)$, the market share $Y(t)$ from equation (3) with $u(t)=\frac{s u m U}{T}$ (the market share for the uniform advertising expenditure), the value of the profit functional $J Y$ for $u(t)=\frac{s u m U}{T}$, and the maximal value of the profit functional $\max _{u} J(u)=V[0]$.

To plot the optimal advertising expenditure $U(k)$ we use the «display» command of Maple.

>display(\{pointU, polygU\});

In order to compare the market share $X(t)$ for the optimal advertising expenditure and the market share $Y(t)$ for the uniform advertising expenditure we display the plots $X(t), Y(t)$ together.

>display(\{pointX, pointY, polygX, polygY\});

\section{Conclusions}

In the paper, we develop a discrete model of optimal advertising since the process of funding the advertising campaign is discrete. It is important that the optimal control 
problem for our new model can be solved explicitly. The model is nonlinear, and the non-linearity depends on a parameter $\sigma, 0<\sigma<1$. We use $\sigma$ to adapt the model to specific markets more precisely. If there is the retrospective statistical information about the dependence of the market share on the cost of an advertising campaign, then we can evaluate this parameter for the analyzed market. However testing of the model on real markets will be an object of future studies. Moreover, it is expected that the model can be used in the problem of optimal control for an oligopoly model of advertising to obtain solutions in closed form.

\section{References}

1. Vidale M.L., Wolfe H.B. An Operation Research Study of Sales Response to Advertising. Operations Research, 1957, vol. 5, no. 3, pp. 370-381. DOI: 10.1287 /opre.5.3.370

2. Sethi S.P. Deterministic and Stochastic Optimization of a Dynamic Advertising Model. Optimal Control Applications and Methods, 1983, vol. 4, issue. 2, pp. 179184. DOI: $10.1002 /$ oca.4660040207

3. Chiarella C., Szidarovszky F. Discrete Dynamic Oligopolies with Intertemporal Demand Interactions. Mathematica Pannonica, 2008, vol. 19, no. 1, pp. 107-115.

4. Gracheva S.S., Pershin M.A. Optimal Advertising Expenditures of a Monopolist with an Only Good in Discrete Linear Model. Upravlenie ekonomicheskimi sistemami: elektronnyy nauchnyy zhurnal [Control of Economic Systems: Electronic Journal], 2013, no. 3, pp. 26-44. (in Russian)

5. Gracheva S.S. Optimization of Advertising Strategy of a Company in Case of NonLinear Function of Demand. Vestnik of Samara State University. Economics and Management, 2014, no. 2 (113), pp. 180-185. (in Russian)

6. Little J.D.C. Aggregate Advertising Models: The State-of-the-Art. Operations Research, 1979, vol. 27, pp. 629-667.

7. Sethi S.P., Prasad A., He X. Optimal Advertising and Pricing in a New-Product Adoption Model. Journal of Optimization Theory and Applications, 2008, vol. 139, no. 2, pp. 351-360. DOI: 10.1007/s10957-008-9472-5

8. Slade M. Product Rivalry with Multiple Strategic Weapons: An Analysis of Price and Advertising Competition. Journal of Economics and Management Strategy, 1995, vol. 4, issue 3, pp. 445-476. DOI: 10.1111/j.1430-9134.1995.00445.x

9. Erickson G.M. Advertising Strategies in a Dynamic Oligopoly. Journal of Marketing Research, 1995, vol. 32, no. 2, pp. 233-237.

10. Sorger G. Competitive Dynamic Advertising: A Modification of the Case Game. Journal of Economics Dynamics and Control, 1989, vol. 13, issue 1, pp. 55-80.

11. Sethi S.P., Thompson G.L. Optimal Control Theory: Applications to Management Science and Economics. New York, Springer, 2000. DOI: 10.1007/0-387-29903-3

12. Zhukovskiy V.I., Kudryavtsev K.N. Equilibrating Conflicts and Applications [Balancing Conflicts and Applications]. Moscow, Lenand Publ., 2012. 
13. Adukova N.V. [A Discrete Model of Optimal Planning of Advertising Expenditures]. Sistemy kompyuternoy matematiki $i$ ih prilozheniya: materialy XVI mezhdunarodnoy nauchnoy conferentsii [Systems of Computer Mathematics and Their Applications: Proceedings of the XVI International Scientific Conference]. Smolensk, SmolSU Publ., 2015, pp. 119-121. (in Russian)

Victor M. Adukov, doctor of physical and mathematical sciences, professor, department of mathematical and functional analysis, South Ural State University, Chelyabinsk, Russian Federation, adukovvm@susu.ac.ru.

Nataliya V. Adukova, graduate student, department of equations of mathematical physics, South Ural State University, Chelyabinsk, Russian Federation, adnatasha94@mail.ru.

Konstantin N. Kudryavtsev, candidate of physical and mathematical sciences, assistant professor, department of mathematical and functional analysis, South Ural State University, Chelyabinsk, Russian Federation, kudrkn@gmail.com.

Received August 18, 2015

УДК 519.863

DOI: $10.14529 /$ jcem 150302

\title{
ОБ ОДНОЙ ДИСКРЕТНОЙ МОДЕЛИ ОПТИМАЛЬНОГО ПЛАНИРОВАНИЯ РЕКЛАМНОГО БЮДЖЕТА
}

\author{
В.М. Адуков, Н.В. Адукова, К.Н. Кудрявцев
}

В большинстве работ по оптимальному планированию рекламного бюджета рассматриваются непрерывные модели. Статьи по моделям с дискретным временем встречаются более редко, т.к. в этом случае трудно получить явное решение. В данной статье предложена новая дискретная модель оптимального планирования рекламного бюджета для продавца-монополиста нового товара. В модели динамика продаж задается нелинейным разностным уравнением. Нелинейность зависит от параметра $\sigma, 0<\sigma<1$, т.е., фактически, рассматривается непрерывное семейство моделей. Дискретные версии модели Видаля - Волфа и модели Сетти являются частными случаями этой модели. Цель продавца максимизировать прибыль к конечному горизонту планирования $T$ с помощью оптимального планирования рекламных расходов. Данная задача является дискретной многошаговой задачей оптимального управления, где управление это расходы на рекламу. Для нашей модели задача оптимального управления может быть решена явно. Для ее исследования используется метод динамического программирования Беллмана. Получены явные рекуррентные соотношения для оптимального управления и доли рынка к моменту времени $t, t=1, \ldots, T$, в предположении, что разностное уравнение в модели имеет решение. Найдены достаточные условия на параметры модели, гарантирующие существование решения. Предложенный алгоритм реализован в виде процедуры OptimalAdvertising в пакете Maple. Проведены численные эксперименты с данной процедурой.

Ключевые слова: рекламные расходы; оптимальное управление; дискретнал модель; динамическое программирование. 


\section{Литература}

1. Vidale, M.L. An Operation Research Study of Sales Response to Advertising / M.L. Vidale, H.B. Wolfe // Operations Research. - 1957. - V. 5, № 3. - P. 370-381.

2. Sethi, S.P. Deterministic and Stochastic Optimization of a Dynamic Advertising Model / S.P. Sethi // Optimal Control Applications and Methods. - 1983. - V. 4, issue 2. - P. 179-184.

3. Chiarella, C. Discrete Dynamic Oligopolies with Intertemporal Demand Interactions / C. Chiarella, F. Szidarovszky // Mathematica Pannonica. - 2008. - V. 19, № 1. P. 107-115.

4. Грачева, С.С. Дискретная задача оптимизации рекламной политики компании в случае линейной модели динамики спроса / С.С. Грачева, М.А. Першин // Управление экономическими системами: электронный научный журнал. - 2013. - № 3 (51). - C. 26-44.

5. Грачева, С.С. Оптимизация рекламной стратегии компании для случая нелинейной функции спроса / С.С. Грачева // Вестник Самарского государственного университета. Серия «Экономика и управление». - 2014. - № 2 (113). - С. 180185.

6. Little, J.D.C. Aggregate Advertising Models: the State-of-the-Art / J.D.C. Little // Operations Research. - 1979. - V. 27. - P. 629-667.

7. Sethi, S.P. Optimal Advertising and Pricing in a New-Product Adoption Model S.P. Sethi, A. Prasad, X. He // Journal of Optimization Theory and Applications. 2008. - V. 139, № 2. - P. 351-360.

8. Slade, M. Product Rivalry with Multiple Strategic Weapons: an Analysis of Price and Advertising Competition / M. Slade // Journal of Economics and Management Strategy. - 1995. - V. 4, issue 3. - P. 445-476.

9. Erickson, G.M. Advertising Strategies in a Dynamic Oligopoly / G.M. Erickson // Journal of Marketing Research. - 1995. - V. 32, № 2. - P. 233-237.

10. Sorger, G. Competitive Dynamic Advertising: a Modification of the Case Game G. Sorger // Journal of Economics Dynamics and Control. - 1989. - V. 13, issue 1. P. 55-80.

11. Sethi, S.P. Optimal Control Theory: Applications to Management Science and Economics / S.P. Sethi, G.L. Thompson. - New York: Springer, 2000. - 152 p.

12. Жуковский, В.И. Уравновешивание конфликтов и приложения / В.И. Жуковский, К.Н. Кудрявцев. - М.: УРСС, 2012. - 304 с.

13. Адукова, Н.В. Дискретная модель оптимального планирования рекламного бюджета / Н.В. Адукова // Системы компьютерной математики и их приложения: материалы XVI Международной научной конференции. - Смоленск: Изд-во СмолГУ, 2015. - С. 119-121. 
Адуков Виктор Михайлович, доктор физико-математических наук, профессор, кафедра математического и функиионального анализа, Южсно-Уральский государственный университет (г. Челябинск, Российская Федерация), adukоvvт@susu.ac.ru.

Адукова Наталия Викторовна, магистрант, кафедра уравнений математической физики, Южно-Уральский государственный университет (г. Челябинск, Российская Федерачия), adnatasha94@mail.ru.

Кудрявцев Константин Николаевич, кандидат физико-математических наук, доцент, кафедра математического и функционального анализа, ЮжноУральский государственный университет (г. Челябинск, Российская Федерация), kudrkn@gmail.com.

Поступила в редакиию 18 августа 2015 г. 